\title{
Disease incidence, severity and changes in morphological characteristics of some high value hybrid genotypes of oil palm (Elaeis guineensis Jacq.) seedlings as influenced by fusarium oxysporum f. sp. Elaeidis
}

\author{
Galdima MADI ${ }^{1}$, Godswill NTSOMBOH-NTSEFONG ${ }^{1,2}$, Georges Frank NGANDO \\ EBONGUE $^{1}$, Aurelie NYAKA NGOBISA ${ }^{1}$ and Victor Désiré TAFFOUO ${ }^{3 *}$
}

\author{
${ }^{1}$ Institute of Agricultural Research for Development (IRAD), P. O. Box 2123 Yaounde, Cameroon. \\ ${ }^{2}$ Laboratory of Genetics \& Plant Improvement, Faculty of Science, University of Yaounde 1, Cameroon. \\ ${ }^{3}$ Department of Plant Biology, Faculty of Science, University of Douala, Cameroon. \\ ${ }^{*}$ Corresponding author; E-mail: dtaffouo@yahoo.com
}

\begin{abstract}
Fusarium oxysporum f. sp. elaeidis (F.o.e) which is a causative agent of vascular wilt disease is the main threat to oil palm (Elaeis guineensis) cultivation in Africa. Its effects are more widely known on adult palms at production stage than on palm trees at the pre-nursery stage. The aim of his study was to evaluate the effects of F.o.e on the morphological parameters and the disease incidence and severity on seedlings during four months of pre-nursery stage. Ten high value hybrid genotypes of germinated seeds, including three tolerant to F.o.e were used. Seedlings were inoculated at four weeks of age with F.o.e. The morphological parameters (height and stem diameter of the seedlings, leaf length and width, leaf area) were recorded every two weeks and the disease incidence and severity on seedlings were determined. All the observed parameters were negatively influenced by F.o.e. Seedling height showed the highest difference $(5.34 \%)$ and two genotypes (T1N and T3F) out of the ten assessed recorded no influence of F.o.e. As these results are not correlated with the internal symptoms of vascular wilt, it is not evident to deduce tolerance of the progeny solely based on F.o.e effects on the growth traits. There was a positive and significant correlation $(\mathrm{r}=0.67, \mathrm{P}<0.05)$ between the index of Fusarium (IF) and the disease severity, between the IF and disease incidence $(\mathrm{r}=0.85, \mathrm{P}<0.01)$. However, the correlation between the IF and seedling morphology was negative and not significant $(\mathrm{r}=-0.17, \mathrm{P}>0.05)$. The morphological parameters of T3N and T5N genotypes initially known to be susceptible to Fusarium wilt were the most affected $(19.05 \%$ and $13.33 \%$ respectively) of the inoculated seedlings compared to control seedlings. T1N initially known to be susceptible here manifested signs of tolerance confirming the observations made on internal symptoms. Moreover, T3F, T2F and T1F progenies recorded an IF $<100$ and have also been morphologically more efficient thus confirming their Fusarium tolerance status. These results may serve as a pre-diagnostic index of Fusarium wilt in oil palm.

(C) 2020 International Formulae Group. All rights reserved.
\end{abstract}

Keywords: Elaeis guineensis, Fusarium oxysporum f. sp. elaeidis, growth parameters, hybrid genotypes, pre-nursery.

\section{INTRODUCTION}

Oil palm is the major source of vegetable oil in the world. Its cultivation is seriously threatened on the African continent mainly by a soil-borne fungus, Fusarium oxysporum f. sp. elaeidis (F.o.e) and causal agent of vascular wilt (Ntsomboh-Ntsefong et al., 2012; 2015). Oil palm (Elaeis guineensis) 
is a perennial, monocotyledonous and heliophyte plant with a fasciculate and densely branched root system, which ensures the mineral nutrition of the palm in the first 40 centimeters from the ground surface (Jourdan et al., 2000). It is mainly cultivated in the wet equatorial zone with temperatures between 18 ${ }^{\circ} \mathrm{C}$ and $32{ }^{\circ} \mathrm{C}$, and an average rainfall of 2500 $\mathrm{mm}$ per year (Goh, 2000). The plant has an economic life span of 25 to 35 years. The fruits of this crop produce two types of oil: crude palm oil extracted from the mesocarp and palm kernel oil extracted from the kernel (Oil world, 2014). Palm oil is used for food purposes (cooking oil, margarine, vanaspati, and shortenings), oleochemicals (detergents, cosmetics) and pharmaceutical purposes (carotenes), health supplement and as a source of biofuel (Ntsomboh-Ntsefong et al., 2012; 2015).

Symptoms of Fusarium wilt disease occur when oil palm seedlings are inoculated with the fungus (Tengoua and Bakoumé, 2008). Fusarium oxysporum f. sp. elaeidis (F.o.e) is a soil-borne pathogenic fungus that invades intact roots then the xylem to cause water stress and hormonal imbalance, with consequent severe yield loss and even death of the palm tree (Cooper, 2011). In Africa, Fusarium vascular wilt is widespread and can cause up to $70 \%$ mortality of palm trees in plantations (Cochard et al., 2005). F.o.e exists in two forms; pathogenic and non-pathogenic, constituting more than half of the Fusarium population of the soil (Edel et al., 2001). The pathogenic form is substantially the most abundant in the rhizosphere of susceptible plant varieties and its virulence varies from one strain to another (Tengoua and Bakoumé, 2008). The visible symptoms of vascular wilt on oil palm are a function of the age of the plant, the stage of infection, the susceptibility of the plant and the environment (Flood, 2006; Ntsomboh-Ntsefong, 2012; Claudine et al., 2019). Isolates of F.o.e obtained from root tissues of herbaceous plant species (Amaranthus spinosus, Eupatorium odoratum, Mariscus alternifolius and Imperata cylindrica) from a plantation in Nigeria were pathogenic to oil palm seedlings (Oritsejafor,
1986). Even pathogenic F.o.e isolates from oil palm may cause vascular wilt on the date palm while isolates of $F$. oxysporum f. sp. Albedinis are pathogenic to oil palm (Paul, 1995).

The identification of vascular wilt symptoms on infected oil palm plants, has been well described by Claudine et al. (2019), Flood (2006) and Ntsomboh-Ntsefong (2012). In oil palm at production stage, Fusarium wilt occurs mainly in two forms; a typical form that leads to palm death two to three months after the onset of the first symptoms, and the chronic form where the palm survives for a few years (Cooper, 2011). In oil palm of 1 to 4 years of age, the disease manifests itself by yellowing and then browning of the middle leaves of the crown, followed by the lower leaves. In the nursery, Fusarium wilt appears only after inoculation of the parasite on the roots manifested by yellowing of the young leaves. Here, internal symptoms are most abundant and are observed on pseudo-bulbs after their dissection (de Franqueville and Diabaté, 1995). The manifestations of Fusarium wilt on the morphological parameters and the disease incidence and severity on seedlings in pre-nursery are still not well described. The aim of this study was to evaluate the effects of Fusarium oxysporum f. sp. elaeidis on the morphological parameters and the disease incidence and severity on seedlings during four months of pre-nursery stage.

\section{MATERIALS AND METHODS}

\section{Study area}

The trial was conducted at the Ekona Regional Center of the Institute of Agricultural Research for Development, located in the Fako Division, Southwest Region of Cameroon. The area lies between $3^{\circ} 54^{\prime} 22^{\prime \prime}$ and $6^{\circ} 29^{\prime} 52^{\prime \prime} \mathrm{N}$ latitude and between $8^{\circ} 30^{\prime} 58^{\prime \prime}$ and $10^{\circ} 6^{\prime} 45^{\prime \prime}$ E longitude (Figure 1).

\section{Plant and fungi material}

Plant material used in this study was ten oil palm seed genotypes (Table 1). Seeds of hybrid genotypes were obtained from the Institute of Agricultural Research for 
Development (IRAD), Specialized Centre for Oil Palm Research of La Dibamba (CEREPAH), Cameroon. These seeds of hybrid genotypes were obtained by controlled pollination at IRAD La Dibamba and pregerminated following the dry heat technique (Ntsomboh-Ntsefong et al., 2015a). They included three tolerant hybrid genotypes [C1001IIF (T1F), C2301IIF (T2F) and C2501IIFX (T3F)] and seven susceptible hybrid genotypes [C1001II (T1N), C2301II (T2N), C2501II (T3N), C2001II (T4N), C2101II (T5N), C1501II (T6N) and C1901II (T7N) (Table 1). Two strains of Fusarium oxysporum $f$. sp. elaeidis (F.o.e) known to be virulent (Tengoua and Bakoumé, 2008) were used for seedling inoculation. Biological materials used in this study were palm fronds and F.o.e isolates. The palm fronds were cut at the level of petioles from infected Dura, Pisifera and Tenera in three blocks of palm trees at the IRAD Ekona research site. F.o.e isolates were collected from brown fibers in the petioles of these palm fronds cut from 30 palm trees infected by fusarium wilt. Soil samples were also collected from around the infected trees (Ntsomboh-Ntsefong et al., 2015a).

\section{Inoculum preparation}

Inoculum preparation was carried out in the palm pathology laboratory at EKONA. Two strains of F.o.e earlier characterized as being aggressive (Tengoua and Bakoume, 2008) were used with Armstrong Fusarium culture medium. Using the procedure of Tengoua (1993), F.o.e strains were purified in an inclined test tube. Then a small fragment was deposited in a test tube containing distilled water that had been sterilized thrice with autoclave at $120^{\circ} \mathrm{C}$ for $45 \mathrm{~min}$. Part of the conidial suspension obtained was collected with a Pasteur pipette and spread in a Petri dish containing NASH medium for $1 \mathrm{~L}$ (peptone $15 \mathrm{~g}$, agar agar $20 \mathrm{~g}$, monopotassium phosphate $1 \mathrm{~g}$, magnesium sulfate $0,5 \mathrm{~g}$, distilled water $1 \mathrm{~L}$, dihydrostreptomycine 1 $\mathrm{mL}$, pentachloronitrobenzene $1 \mathrm{~g}$, autoclave at $120{ }^{\circ} \mathrm{C}$ for $50 \mathrm{~min}(\mathrm{pH}=6.5)$. After spore germination, a fragment was collected and placed on mycelium medium in a test tube. Then a fragment of this medium containing the fungus was cut and introduced in $75 \mathrm{~mL}$ of sterile Armstrong medium in a conical flask. This was agitated every $10 \mathrm{~min}$ for four days to enhance multiplication of Fusarium. Then 2 $\mathrm{mL}$ of the solution obtained were put in 100 $\mathrm{mL}$ of sterile Armstrong medium in roux bottles which were inclined on a surface sterilized with alcohol and flaming. For rapid multiplication of Fusarium, this was agitated every $10 \mathrm{~min}$ for 8 days. The solution obtained was mixed and ground for 10 secs with the laboratory blender (NtsombohNtsefong et al., 2015b).

\section{Inoculation of seedlings in the pre-nursery}

The pre-nursery Fusarium wilt test was performed with a completely randomized block design involving inoculated seedlings and non-inoculated seedlings (as controls) using Fusarium inoculum previously prepared with sterilized distilled water in a Roux bottle (Figure 2). Inoculation was done at least one and a half months after transplanting the pregerminated seeds in the nursery following the steps described by Renard et al. (1972).

\section{Morphological characteristics}

Seedlings growth (height, stem diameter, number of leaves, leaf area, length and width of leaf) were evaluated using 40 plants for each hybrid genotype in four replicates. The height was measured every week with a graduated ruler. Stem diameter was measured with a caliper and leaf area was measured every week and calculated using the method described by Tailliez and Ballo (1992).

\section{Disease incidence on seedlings}

The disease incidence (I) on seedlings were determined by Tucker and Chakraborty (1997) methods. $\mathrm{I}=(\mathrm{Nm} / \mathrm{Nt}) \times 100$

with $\mathrm{I}$ : disease incidence; $\mathrm{Nm}$ : number of seedlings infected ; $\mathrm{Nt}$ : number of seedlings infected and uninfected 


\section{Desease severity on seedlings}

The disease severity ( $\mathrm{S}$ ) on seedlings were determined by Tucker and Chakraborty (1997) methods.

$\mathrm{S}=[\Sigma(\mathrm{a} \times \mathrm{b}) / \mathrm{n}] \times 100$

with $\mathrm{S}$ : Infection severity, $\Sigma(\mathrm{a} \times \mathrm{b})$ : sum of the products of the number of seedlings infected (a) and the corresponding degree of infection (b) ; $\mathrm{n}$ : number of seedlings infected.

\section{Tolerance index of Fusarium}

The index (I) of tolerance is attributed to each progeny according to the procedure described by Renard et al. (1972). Based on the results of the nursery test, the progenies used for the production of seeds tolerant to vascular wilt are classified according to their categories:

$I=\frac{\% \text { infected seedlings and wilthered of progeny } A}{\% \text { infected seedlings and wilthered of all progeny }} \times 100$
I < 90: high tolerance

$90<$ I < 100: moderate tolerance

$100<$ I $<120$ : sensitive

I $>120$ : highly sensitive

\section{Statistical analysis}

Data are presented in terms of mean $( \pm$ standard deviation). The data collected on the various morphological parameters were entered in the Excel software and analyzed with SPSS Statistics 17.0 (2012) software. The data were analyzed for variance (ANOVA) to detect the difference in Fusarium wilt effect. Separation of the means was performed at the $5 \%$ threshold by the DUNCAN test. A correlation test between the different parameters and a hierarchical classification test between the seeds of hybrid genotypes were also carried out.

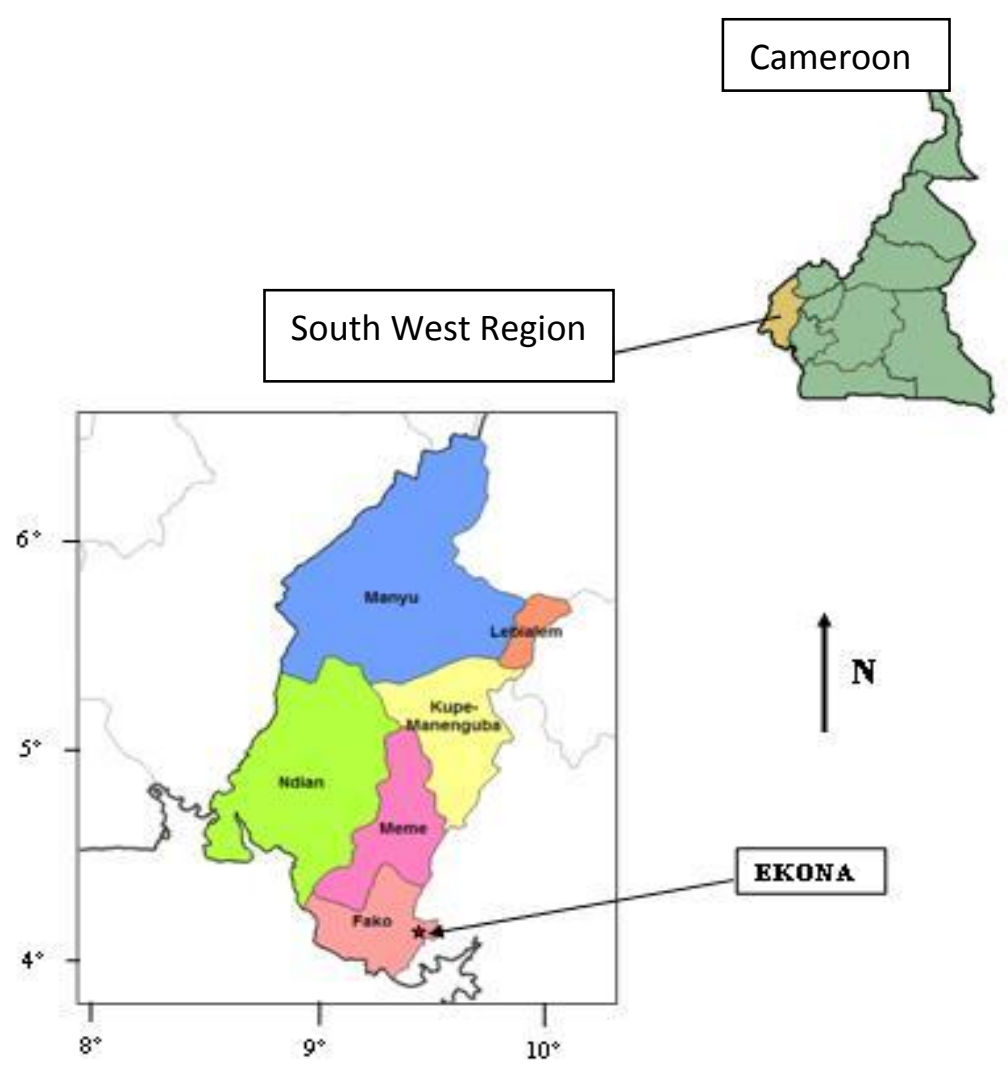

Figure 1: Study area. 
Table 1: Seeds of hybrid genotypes oil palm used in this study.

\begin{tabular}{cccc}
\hline $\begin{array}{c}\text { Code of hybrid } \\
\text { genotypes }\end{array}$ & $\begin{array}{c}\text { Seed of hybrid } \\
\text { genotypes }\end{array}$ & Female progeny code & $\begin{array}{c}\text { Male progeny } \\
\text { code }\end{array}$ \\
\hline T3F & C2501IIFX & LM 13533 & LM 19029 \\
T3N & C2501 II & LM 17685 & LM 17685 \\
T6N & C1501 II & LM 17115 & LM 18978 \\
T1F & C1001 IIF & LM 19106 & LM 19029 \\
T1N & C1001 II & LM 18801 & LM 18106 \\
T2F & C2301 IIF & LM 18745 & LM 19029 \\
T4N & C2001 II & LM 17164 & LM 18978 \\
T7N & C1901 II & LM 19171 & LM 18978 \\
T5N & C2101 II & LM 17163 & LM 18978 \\
\hline
\end{tabular}
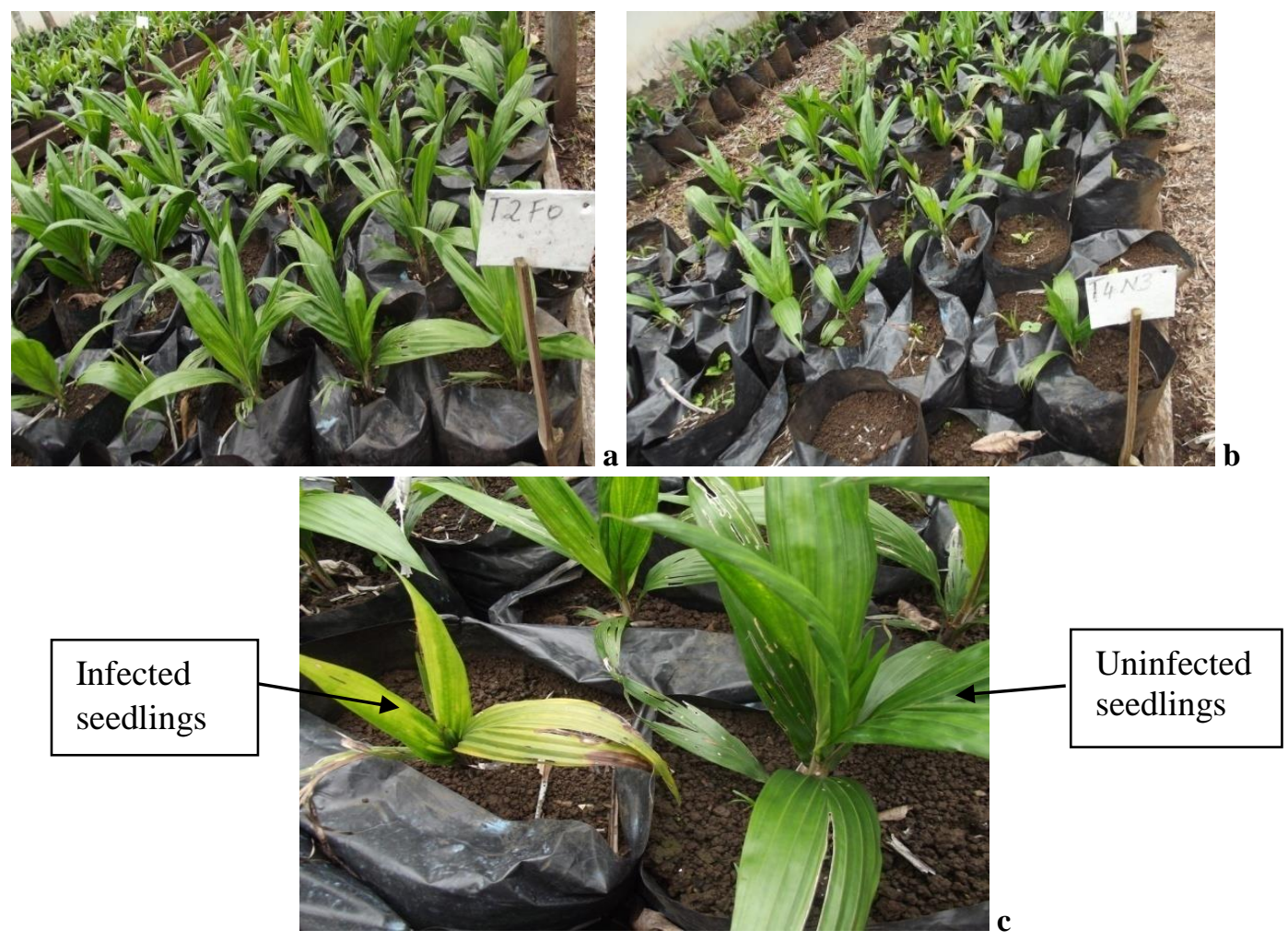

Figure 2: Inoculation of hybrid seedlings in the pre-nursery. a: non-inoculated seedlings (control); b: inoculated seedlings; c: samples of non-inoculated and inoculated seedlings. 


\section{RESULTS}

\section{Plant growth parameters Seedlings height}

The mean height of the un-inoculated seedlings $(27.19 \pm 0.51 \mathrm{~cm})$ was generally higher than that of the inoculated seedlings $(25.48 \pm 0.46 \mathrm{~cm})$ for all the hybrid genotypes except for $(\mathrm{T} 3 \mathrm{~F}, \mathrm{~T} 1 \mathrm{~N})$ where the tendency was reversed (Figure 3). The observed difference between the inoculated seedlings and the controls were $5.95 \%$, with the T3N hybrid genotype having the greatest difference (17.23\%). The T1F and T6N hybrid genotypes were noted to be the best performers $(28.45 \pm$ $0.56 \mathrm{~cm}$ ).

\section{Stem diameter}

Figure 4 shows a better performance of stem diameter of the control seedlings $(0.86 \pm$ $0.04 \mathrm{~cm}$ ) compared to the inoculated seedlings $(0.81 \pm 0.03 \mathrm{~cm})$ in seven hybrid genotypes with an overall difference of $5.34 \%$ and with the $\mathrm{T} 3 \mathrm{~N}$ genotypes having the greatest difference of $28.05 \%$. The standard deviations for the stem diameter of the seedlings are very variable from one hybrid genotype to another and show a greater dispersion than that of the height of the seedlings. Seedlings of Fusarium wilt-resistant hybrid genotypes (T1F and T2F) recorded the diameters below their controls contrary to expectations.

\section{Leaf length}

Inoculated seedlings globally recorded leaf length $(15.76 \pm 0.04 \mathrm{~cm})$ lower by $1.12 \%$ compared to control seedlings $(15.91 \pm 0.06$ $\mathrm{cm}$ ) (Figure 5). T3N hybrid genotype which is susceptible to Fusarium witnessed the largest difference $(16.72 \%)$. On the other hand, hybrid genotypes T1N and T3F had a reversed tendency with respect to the majority. The standard deviations for the lengths of the leaves being small and very variable (3.1 to 4.4) imply a weak dispersion of values around the mean.

\section{Width of leaves}

In a leaf width, the results obtained shows a better behavior of non-inoculated seedlings in the majority of hybrid genotypes except two (T1N and T3F) where inoculated seedlings behave better than controls (Figure 6). Overall, the leaf width of the inoculated seedlings $(3.05 \pm 0.02 \mathrm{~cm})$ was $2.78 \%$ lower than that of the control seedlings $(3.13 \pm 0.04$ $\mathrm{cm})$. In the $\mathrm{T} 1 \mathrm{~N}$ and T3F hybrid genotypes, the leaves of the inoculated seedlings were wider than those of the non-inoculated seedlings. The distribution of the variable around the mean shows a low dispersion according to the standard deviations ( 0.4 to $0.9)$.

\section{Leaf area}

The leaf area has significant differences with several subsets (Figure 7). The results show a good performance of the T6N and T3N hybrid genotypes within the control seedlings and of the T1N and T6N hybrid genotypes within the non-inoculated seedlings and which are also non-tolerant. However, in general, the leaf area of the control seedlings was $3.68 \%$ higher than those inoculated. Inoculated seedlings whose foliar surfaces are superior to controls in $\mathrm{T} 1 \mathrm{~N}$ and $\mathrm{T} 3 \mathrm{~F}$ are also observed. The standard deviations for the leaf area are fairly high (10.3 to 16.4) indicating a wide dispersion of values around the means.

\section{Number of leaves.}

There is a slight difference $(1.40 \%)$ between the numbers of leaves of noninoculated plants which is higher than that of inoculated plants, although many seedlings exhibit contradictory tendencies (Figure 8). The standard deviations (1.3 to 1.7) also show a strong dispersion of values around the means.

\section{Variance analysis of morphological parameters}

The leaf area was strongly correlated with the width $(\mathrm{r}=0.94, \mathrm{P}<0.01)$ and the length $(r=0.91 ; P<0.01)$ of the leaves, indicating that it was effectively obtained from these parameters (Table 2). On the other hand, the number of leaves was not correlated with any other morphological parameter. The leaf area also has a strong correlation $(\mathrm{r}=$ 
$0.89, \mathrm{P}<0.01)$ with the height of the seedlings and slightly with the stem diameter.

\section{Analysis of the variance of the Fusarium wilt effect on morphological traits}

The results of the analysis of variance (Table 3) show significant differences for all the observed parameters. These results make it possible to detect the difference in susceptibility of the genotypes to Fusarium oxysporum $f$. sp. elaeidis.

\section{Incidence of Fusarium}

The degree of infection is assessed by the incidence of the Fusarium on bulb and leaves (Figure 9). The incidence is determined by the relative number of seedlings that show symptoms of the disease. The variation in the incidence of the disease was observed both on the bulbs and on the leaves (Figure 9). It is observed that the incidence shows the higher infection rate on the bulbs than on the leaves (Figure 9). The correlation between disease incidence and seedling morphology was not significant $(\mathrm{P}>0.05)$.

\section{Severity of Fusarium}

The degree of infection is also assessed by the severity of Fusarium. The severity is determined by the rate of spread of symptoms on the leaves and bulb of the plant (Figure 10). The results obtained showed that the severity of the disease is higher in the leaves than in the bulbs (Figure 10), which means that once the seedling is attacked, the symptoms of the disease develop much more on the leaves than on the bulb. The correlation between disease severity and seedlings morphology was not significant $(\mathrm{P}>0.05)$.

\section{Index of Fusarium}

The Fusarium wilt index is the essential parameter in determining the tolerance or not of a hybrid genotype to Fusarium oxysporum. Table 4 presents the distribution of the index of Fusarium between seed hybrid genotypes. It can be noted that among the 5 seed hybrid genotypes that have a Fusarium count less than 100, the first three (T3F, T1N and T1F) hybrid genotypes have also always been morphologically more efficient. Among these genotypes with a low index of Fusarium, three (T3F, T1F, and T2F) are hybrid genotypes that confirm their status as highly tolerant while $\mathrm{T} 1 \mathrm{~N}$ and $\mathrm{T} 7 \mathrm{~N}$ hybrid genotypes are potential tolerant. There was a positive and significant correlation $(\mathrm{r}=0.67, \mathrm{P}$ $<0.05$ ) between the Fusarium index and the severity disease, between Fusarium index and incidence of disease $(\mathrm{r}=0.85, \mathrm{P}<0.01)$. However, the correlation between Fusarium index and seedling morphology was negative and not significant $(\mathrm{r}=-0.17, \mathrm{P}>0.05)$.

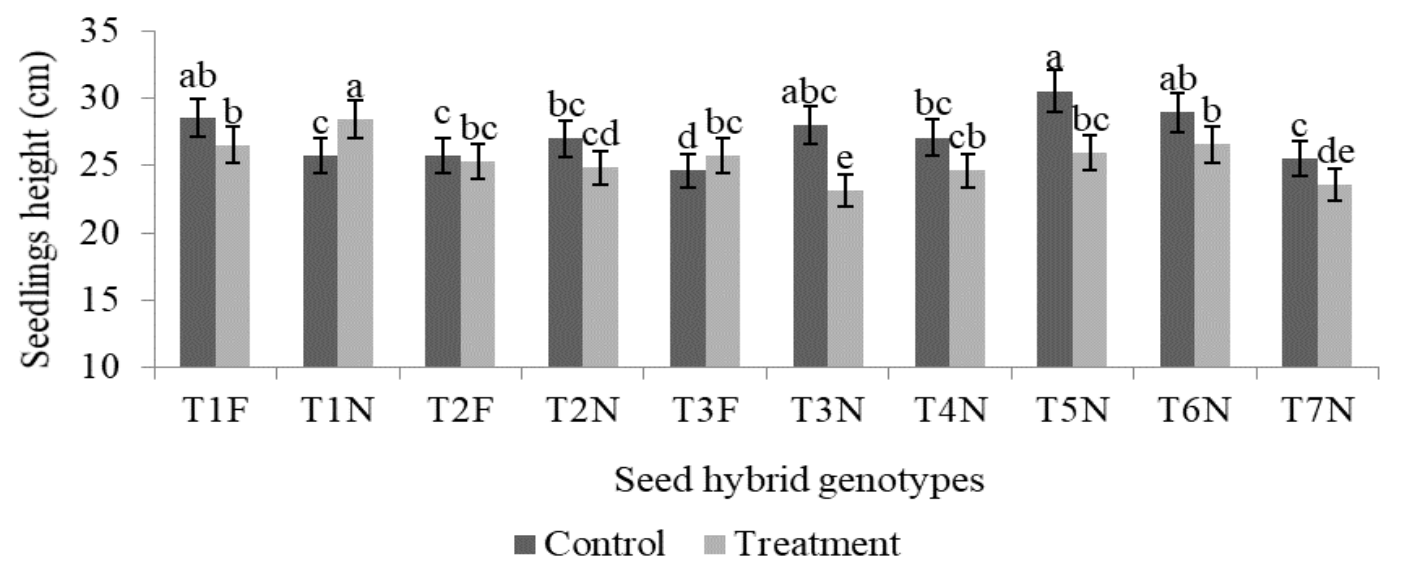

Figure 3: Comparison of the heights of the inoculated seedlings and the non-inoculated seedlings (control). Hybrid genotypes from the same group with the same letters are not significantly different 


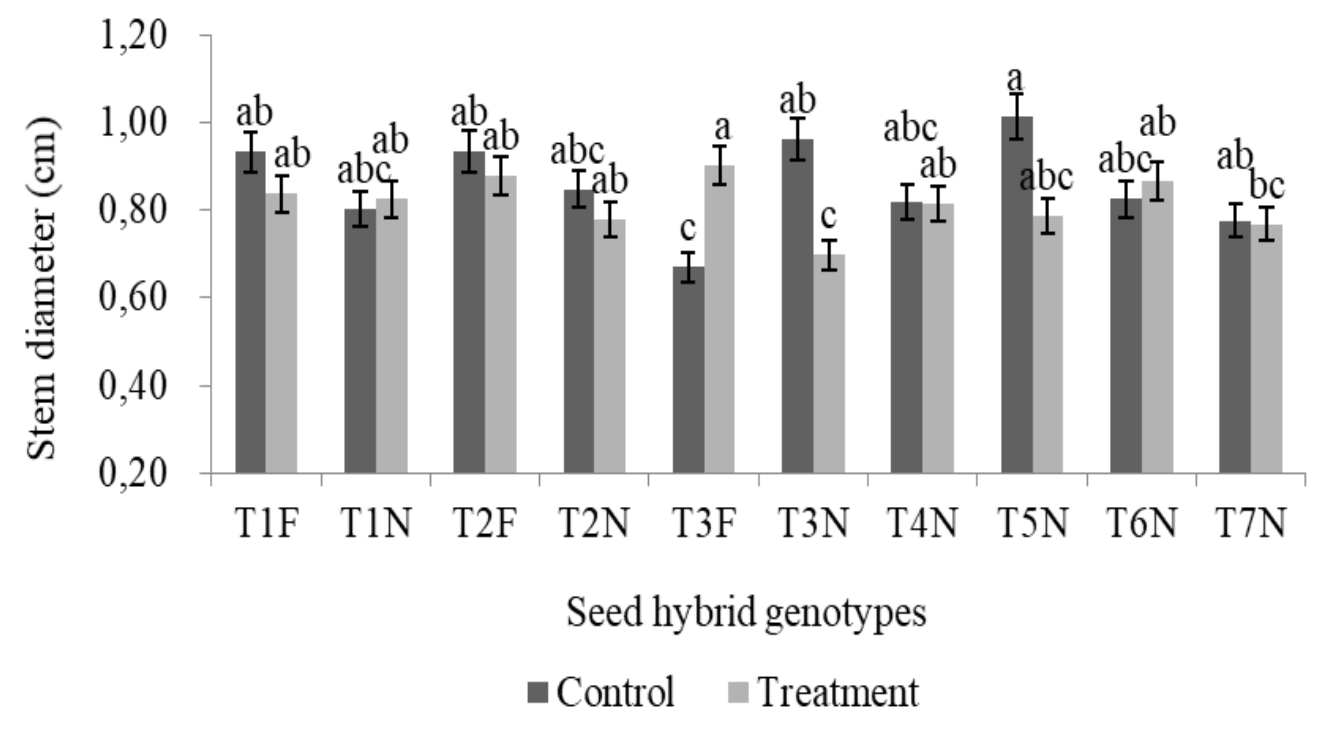

Figure 4: Comparison of stem diameter of inoculated seedlings and non-inoculated seedlings (control). Hybrid genotypes from the same group with the same letters are not significantly different

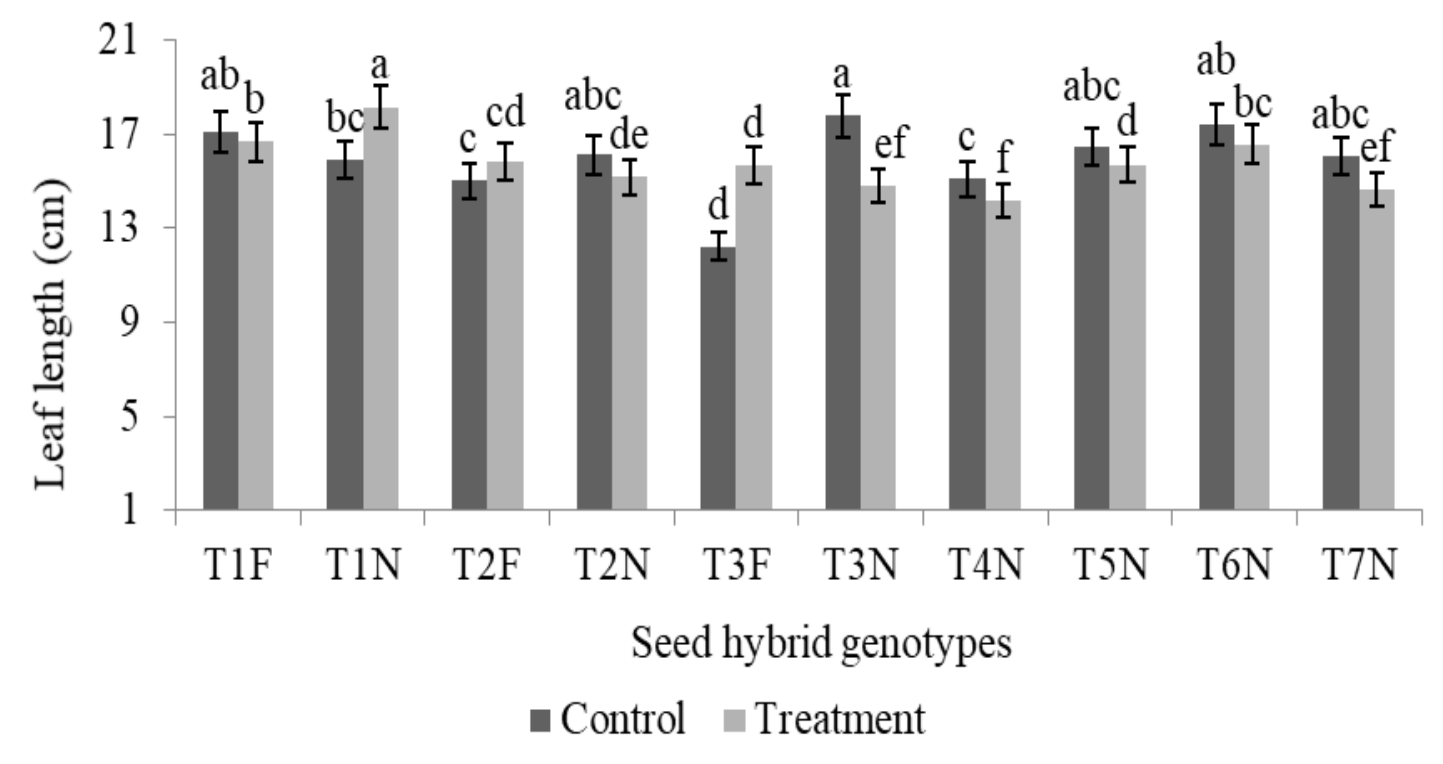

Figure 5: Comparison of leaf length of inoculated seedlings and non-inoculated seedlings (control). Hybrid genotypes from the same group with the same letters are not significantly different. 


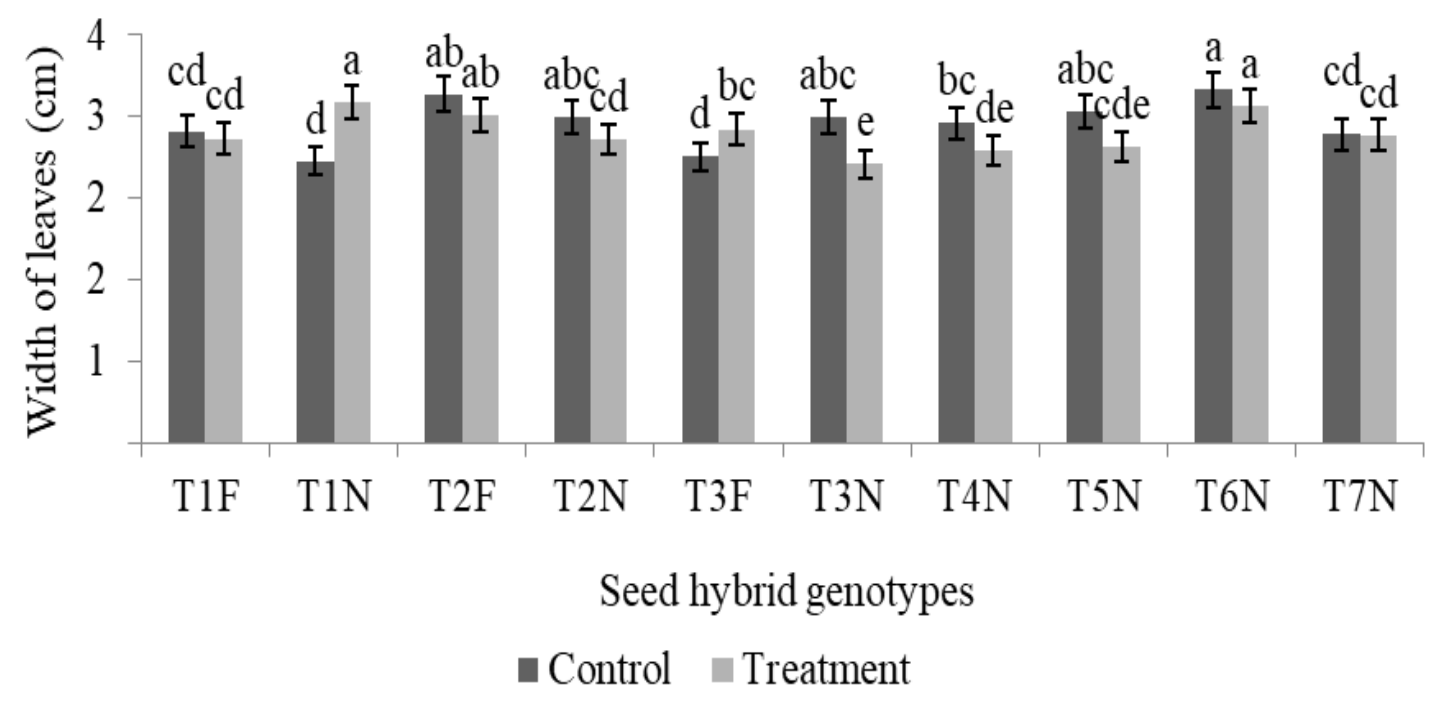

Figure 6: Comparison of leaf width of inoculated seedlings and non-inoculated seedlings (control). Hybrid genotypes from the same group with the same letters are not significantly different.

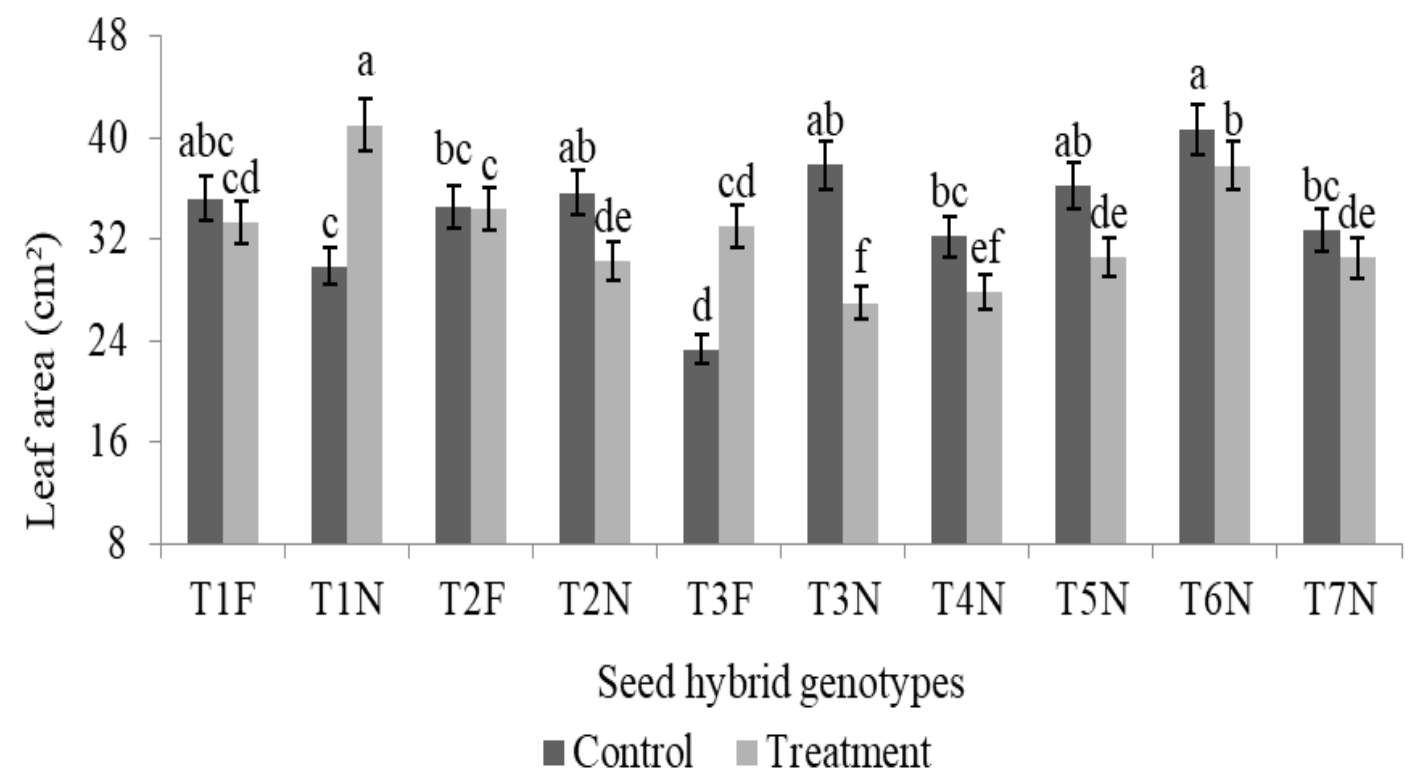

Figure 7: Comparison of the leaf area of the inoculated seedlings and the non - inoculated seedlings (control). Hybrid genotypes from the same group with the same letters are not significantly different. 


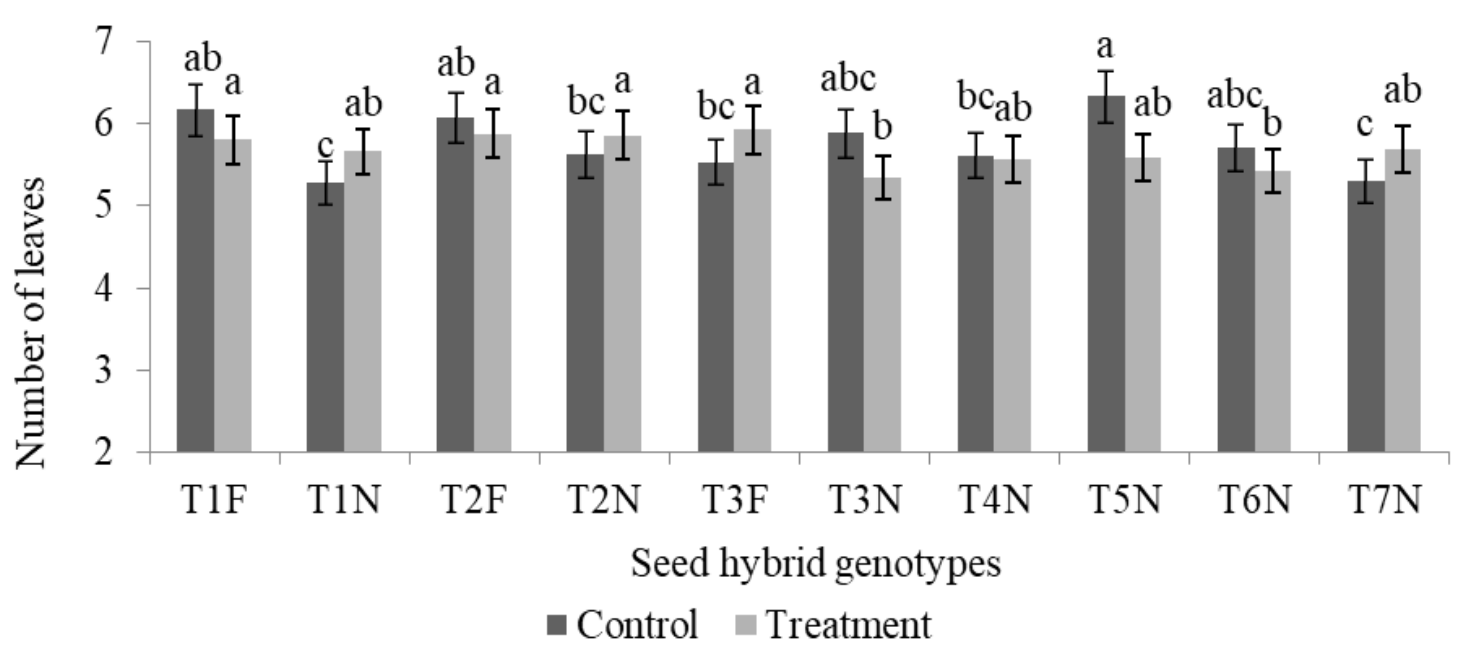

Figure 8: Comparison of the number of leaves of inoculated seedlings and of non-inoculated seedlings (control). Hybrid genotypes from the same group with the same letters are not significantly different.

Table 2: Correlations between different growth parameters.

\begin{tabular}{lllllll}
\hline Parameters & Leaf area & $\begin{array}{l}\text { No. of } \\
\text { leaves }\end{array}$ & $\begin{array}{l}\text { Leaf } \\
\text { width }\end{array}$ & $\begin{array}{l}\text { Leaf } \\
\text { length }\end{array}$ & $\begin{array}{l}\text { Stem } \\
\text { diameter }\end{array}$ & $\begin{array}{l}\text { Seedling } \\
\text { height }\end{array}$ \\
\hline Leaf area & 1 & & & & & \\
No. of leaves & $0,16^{\mathrm{ns}}$ & 1 & & & & \\
Width of leaf & $0,94^{* *}$ & $0,21^{\mathrm{ns}}$ & 1 & & & \\
Length of leaf & $0,91^{* *}$ & $0,02^{\mathrm{ns}}$ & $0,72^{*}$ & 1 & & \\
Stem diameter & $0,64^{*}$ & $0,60^{\mathrm{ns}}$ & $0,69^{*}$ & $0,42^{\mathrm{ns}}$ & 1 & 1 \\
Seedling height & $0,89^{* *}$ & $0,15^{\mathrm{ns}}$ & $0,73^{*}$ & $0,89^{* *}$ & $0,61^{\mathrm{ns}}$ & 1 \\
\hline
\end{tabular}

** Correlation is significant at $\mathrm{P}<0.01$, ${ }^{*}$ Correlation is significant at $\mathrm{P}<0.05,{ }^{\text {ns }}$ Correlation is non-significant.

Table 3: Analysis of the variance of the Fusarium wilt effect on morphological traits of oil palm seedlings in pre-nursery.

\begin{tabular}{lllllll}
\hline Parameters & & $\begin{array}{l}\text { Sum of } \\
\text { squares }\end{array}$ & $\begin{array}{l}\text { Degree of } \\
\text { freedom }\end{array}$ & $\begin{array}{l}\text { Mean } \\
\text { squares }\end{array}$ & F & p \\
\hline Seedling height & between groups & 3773.19 & 9 & 419.24 & 10.48 & $0.00^{* *}$ \\
Stem diameter & between groups & 5.62 & 9 & 0.62 & 2.53 & $0.01^{*}$ \\
Leaf length & between groups & 2103.94 & 9 & 233.77 & 18.34 & $0.00^{* *}$ \\
Leaf width & between groups & 60.14 & 9 & 6.68 & 11.35 & $0.00^{* *}$ \\
No. of leaves & between groups & 49.34 & 9 & 5.48 & 2.52 & $0.01^{*}$ \\
Leaf area & between groups & 30575.88 & 9 & 3397.32 & 17.83 & $0.00^{* *}$ \\
\hline ***Significant at $\mathrm{P}<0.05$ and $\mathrm{P}<0.01$, rective
\end{tabular}

****Significant at $\mathrm{P}<0.05$ and $\mathrm{P}<0.01$, respectively, ns non-significant. 
- Bulb Leaves

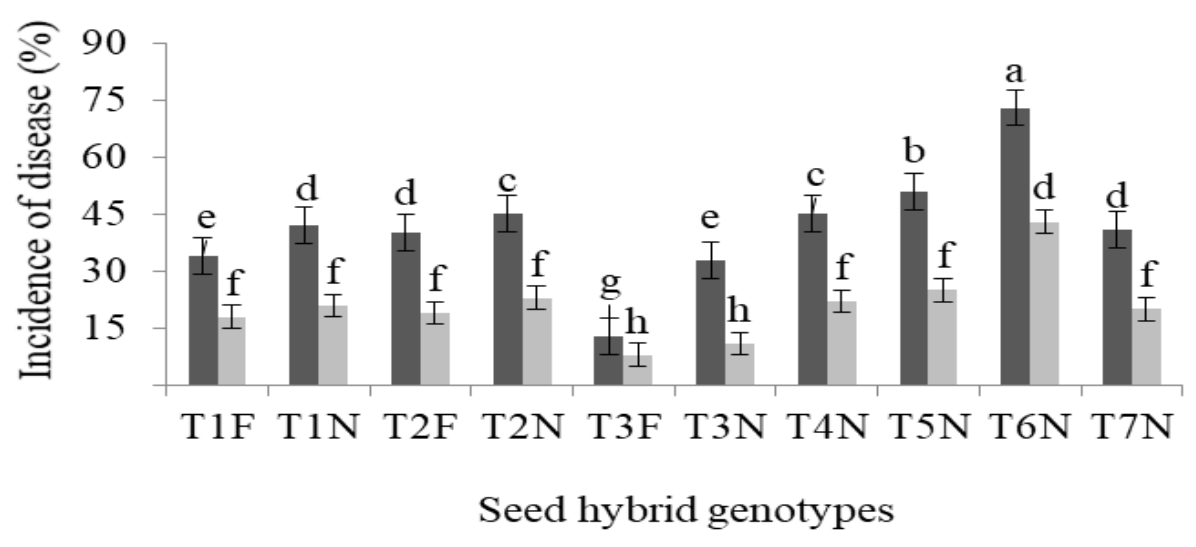

Figure 9: Incidence of Fusarium wilt observed in the bulb and leaves. Hybrid genotypes from the same group with the same letters are not significantly different.

aulb Leaves

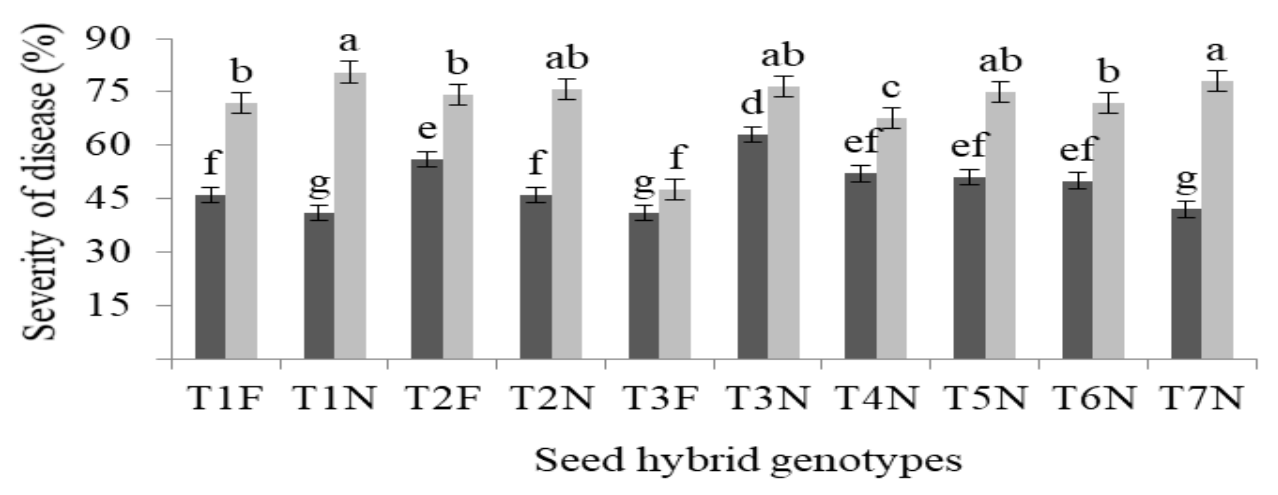

Figure 10: Severity of the Fusarium wilt observed in the bulb and leaves of inoculated seedlings. Hybrid genotypes from the same group with the same letters are not significantly different.

Table 4: Tolerance index of Fusarium of different hybrid genotypes.

\begin{tabular}{crc}
\hline Classification & Genotypes & Index de wilt \\
\hline 1 & T3F & 22 \\
2 & T1N & 49,5 \\
3 & T1F & 66 \\
4 & T7N & 77 \\
5 & T2F & 93,5 \\
6 & T4N & 104,4 \\
7 & T3N & 109,9 \\
8 & T5N & 120,9 \\
9 & T2N & 131,9 \\
10 & T6N & 164,9 \\
\hline
\end{tabular}




\section{DISCUSSION}

The morphological difference observed between inoculated and non-inoculated seedlings shows the effects of Fusarium wilt which led to the retardation of growth of the different parameters of the inoculated seedlings. This corroborates the results obtained in several studies (Flood, 2006; Voui Bi et al., 2016; Claudine et al., 2019; Kenneth et al., 2019). The description of the effects of Fusarium wilt on adult oil palms shows that all morphological parameters, namely palm height and diameter, leaf length and width, leaf area are similar to the results of our study and correspond to the typical symptoms of Fusarium wilt (Gaetán and Madia, 2007; Ntsomboh-Ntsefong, 2012). However, the morphological parameters are affected differently, the height of the seedlings being the most affected. This makes it possible to understand why this same phenomenon is most remarkable on adult palm trees presenting typical symptoms. It is shown that Fusarium affects the growth of certain plants such as rice (Oriza sativa) by reducing the number and length of roots (Hinde et al., 2009). In a study on the pathogenicity involving inoculation with different Fusarium species, it was also found that Fusarium species strongly affect germination and root growth of pine seedlings. The same authors found that pine seeds were more sensitive to infection where the germination and root growth inhibition were more important (Lazreg et al., 2014). It has also been reported that Fusarium species affect germination, root growth, shoot growth and the index vigour in Oriza sativa (Lazreg et al., 2013). Our leaf length and foliar surface results were also similar to those obtained on nursery-damaged (wilted by Fusarium) and water stressed seedlings (Flood, 2006). The correlation between the different morphological parameters (height and diameter of palm trees, leaf length and width, leaf area) shows that they all undergo growth retardation due to the effects of Fusarium wilt. In vitro and in vivo experiments with Fusarium solani were also reported to show severe inhibitory effect on morphology (growth and development) of pea cultivars (Smykalová and Griga, 2011). Growth parameters of pea (Pisum sativum L.) were also influenced negatively after infection with Fusarium oxysporum f. sp. Pisi (Tariq et al., 2015). Morphological parameters such as those measured in this study are important indicators for potential uptake of water and nutrients (Himmelbauer et al., 2004; Yergeau et al., 2006; Da Silva et al., 2016). However, the morphological parameters observed on the seed of hybrid genotypes tested in this study are not correlated with the internal symptoms observed on the same hybrid genotypes by Ntsomboh-Ntsefong et al. (2015b). These observations are similar to those of Buchanan (1999) who have shown that the visible symptoms of Fusarium wilt are much uncorrelated to internal symptoms. It is therefore inappropriate to speculate on the tolerance of progenies on the basis of the effects of Fusarium wilt on morphological parameters. The overlapping classification of the inoculated seedling hybrid genotypes is necessarily linked to the difference in sensitivity of both hybrid genotypes and morphological parameters to Fusarium.

The incidence of Fusarium wilt that we observed is similar to that of Yergeau et al. (2006) in a study in which we took into account the different types of symptoms, expressed or not, healthy-looking palms on which observations were made on their stipe to detect any presence of brown fibers. The number of seedlings infected at the level of the bulb being higher than that observed at the leaf level is explained by the fact that the disease appears first on the bulb and a few days later on the leaves, hence the need to observe both internal and external symptoms of Fusarium wilt for characterization is necessary (Ntsomboh-Ntsefong et al., 2015a). The progenies considered as non-tolerant and which proved to be as efficient as the proven tolerant progenies, could be justified by the insufficiency of root contamination by the pathogen because of the low roots and consequently have no openings to allow penetration of the pathogen (Hamel et al., 2005). The tests initially carried out for the characterization of these progenies were not 
under the same environmental conditions (Ntsomboh-Ntsefong et al., 2015a) which constitute an important factor in the behavior of plants (Goh, 2000). Validation of the tolerance of progeny to Fusarium wilt is conditioned by confirmation in plantation of results obtained in pre-nurseries (Allou et al., 2003; Lazreg et al., 2014). The present work showed that the T1N and T7N which have a Fusarium index lower than 100 but considered as non-tolerant, would have been invalidated at the level of the plantation; in this case the results obtained can be in agreement with those of Chang et al. (2014) who found a strong stability of the pathogenicity. These results therefore indicate that seedling resistance assessment tests are of general significance. The correlation between incidence, severity, and Fusarium index indicates that they are closely related, so Fusarium tolerance could be inferred from incidence or severity. The environmental conditions were favorable to the expression of the pathogen which continued to evolve in an environment from which it is derived. It is therefore estimated that the variations in the different parameters observed are mainly due to the nature of the progenies.

\section{Conclusion}

This study showed that all growth parameters were strongly correlated, with plant height being the most affected parameter with $5.95 \%$ less of inoculated seedlings compared to control seedlings. On the other hand, leaf length was the least delayed parameter. There were also two hybrid genotypes (T1N and T3F) among the ten that showed no morphological symptoms of Fusarium wilt, whereas the T3N and T5N genotypes initially known to be susceptible to Fusarium wilt were the most affected (19.05\% and $13.33 \%$ respectively) of the inoculated seedlings compared to the control seedlings. T1N initially known to be susceptible to Fusarium wilt manifested signs of tolerance confirming the observations made in this study on internal symptoms. Moreover, T3F, $\mathrm{T} 2 \mathrm{~F}$ and $\mathrm{T} 1 \mathrm{~F}$ hybrid genotypes recorded an $\mathrm{IF}<100$ and have also been morphologically more efficient thus confirming their Fusarium tolerance status. The correlation between incidence, severity, and Fusarium index indicates that they are closely related, so Fusarium tolerance could be inferred from incidence or severity. These results may serve as a pre-diagnostic index of Fusarium wilt in oil palm.

\section{COMPETING INTERESTS}

There is no competing interests for this article.

\section{AUTHORS' CONTRIBUTIONS}

GM: methodology, statistics, interpretation, draft of manuscript, proof reading. G N-N: conceptualization, methodology, experimentation, interpretation, draft of original manuscript, proof reading and editing. GFNE: conceptualization, interpretation, writing and reviewing. ANN: draft and editing of manuscript. VDT: interpretation, writing and reviewing.

\section{ACKNOWLEDGEMENTS}

The authors express their heartfelt gratitude to Dr. Koona Paul who inspired the initiation of this research project and gave us the initial opportunity to intervene in the phytopathology unit of CEREPAH. We are grateful to Dr. Echu Kingsley, former Chief of South West Regional Research Centre for supporting the research with an enabling environment at IRAD Ekona. Thanks also go to Dr. Tengoua Fabien whose previous works on characterization of F.o.e samples facilitated our understanding and the realization of this research work. We thank Mr. Eloundou Antoine, Mr. Nyamuka Tita Daniel, Epoh Nguea Toussaint and all the students who were on internship in the phytopathology unit during the realization of this study for their technical support. Finally, we present our sincere gratitude to the specialized Centre for Oil Palm Research of La Dibamba and the hierarchy of the Institute of Agricultural Research for Development for logistical support and the provision oil palm hybrid seeds used in this experiment. 


\section{REFERENCES}

Allou K, Ahoussou N, Ake S, Diabate S, De Franqueville H. 2003. Behavior of oil palm clones in the field in high density zones of F.O.E in Ivory Coast. Agronomie Africaine, 15: 29-38.

Buchanan AG. 1999. Molecular genetic analysis of Fusarium oxysporum wilt resistance in oil palm. Ph.D. Thesis, Bath University, Bath.

Chang T-H, Lin Y-H, Chen K-S, Huang J-W, Hsiao S-C, Chang P-F. 2014. Cell wall reinforcement in watermelon shoot base related to its resistance to Fusarium wilt caused by Fusarium oxysporum f. sp. Niveum. Journal of Agricultural Science, 1-10.

DOI: 10.1017/S0021859614000057

Claudine KS, Koussinou L, Adandonon A, Nodichao L. 2019. Distribution and incidence of Fusarium wilt in oil palm in Benin. Journal of Applied Biosciences, 135: 13831-13839. DOI: https://dx.doi.org/10.4314/jab.v135i1.9

Cochard B, Philippe A, Tristan DG. 2005. Oil palm genetic improvement and sustainable development. OCL., 12: 141147. DOI: https://doi.org/10.1051/ocl.2005.0141

Cooper RM. 2011. Fusarium wilt of oil palm: A continuing threat to South East Asian plantations. The Planter-Kuala Lumpur, 87(1023): 409-418.

Da Silva MP, Tylka GL, Munkvold GP. 2016. Seed treatment effects on maize seedlings co-infected with Fusarium spp. and Pratylenchus penetrans. Plant Disease, 100: 431-437. DOI: https://dx.doi.org/10.1094/PDIS-03-150364-RE

De Franqueville H, Diabate S. 1995. La fusariose du palmier à huile en Afrique de l'Ouest. Plantation Recherche Développement, 24: 5-13.

Edel V, Steinberg C, Gautheron N, Recorbet G, Alabouvette C. 2001. Genetic diversity of Fusarium oxysporum populations isolated from different soils in France. FEMS Microbiology Ecology, 36(1): 61-71. DOI: https://doi.org/10.1111/j.1574-

6941.2001.tb00826.x

Flood J. 2006. A Review of Fusarium Wilt of Oil Palm Caused by Fusarium oxysporum f. $\quad$ sp. elaeidis. Phytopathology, 96(6): 660-662. DOI: 10.1094/PHYTO-96-0660

Gaetán SA, Madia M. 2007. Occurrence of Fusarium wilt caused by Fusarium oxysporum on common sage in Argentina. Plant Disease, 90(6): 833. https://doi.org/10.1094/PD-90-0833A

Goh KJ. 2000. Climatic requirements of the oil palm for high yields. In Managing oil palm for high yields: agronomic principles, Goh KJ. (ed.). Malaysian Society Soil Science and Param Agriculture Surveys: Kuala Lumpur; 117.

Hamel C, Vujanovic V, Nakano-Hylander A, Jeannotte R, St-Arnaud M. 2005. Factors associated with Fusarium crown and root rot of asparagus outbreaks in Quebec. Phytopathology, 95: 867-873. DOI: 10.1094 / PHYTO-95-0867

Himmelbauer ML, Loiskandl W, Kastanek F. 2004. Estimating length, average diameter and surface area of fine roots using two different image analyses systems. Plant and Soil, 260: 111-120. DOI: 10.1023/B: PLSO.0000030171.28821.55

Hinde Boudoudou H, Hassikou R, Ouazzani Touhami A, Badoc A, Douira A. 2009. First manifestations of Fusarium wilt on germination and rice seedlings. Bulletin de la Société de Pharmacie de Bordeaux, 148: 45-54. DOI: 10.1094 / PDIS-94-91170A.

Jourdan C, Michaux-Ferrière N, Perbal G. 2000. Root System Architecture and Gravitropism in the Oil Palm. Annals of Botany, 85: 861-868. DOI: 10.1006/anbo.2000.1148

Kenneth GP, Lindel MC, Wayne TO, David WT. 2019. The epidemiology of Fusarium wilt of banana. Frontiers in Plant Science, 10: 1395. DOI: https://doi.org/10.3389/fpls.2019.01395

Lazreg F, Belabid L, Sanchez J, Gallego E, Garrido-Cardenas JA, Elhaitoum A. 
2013. First report of Fusarium acuminatum causing damping off disease on Aleppo pine in Algeria. Plant Disease, 4: $557 . \quad$ DOI : doi/abs/10.1094/PDIS-06-12-0608-PDN

Lazreg F, Belabid L, Sanchez J, Gallego E, Bayaa B. 2014. Pathogenicity of Fusarium spp. associated with diseases of Aleppo-pine seedlings in Algerian forest nurseries. Journal of Forest Science, 60(3): 115-120.

Ntsomboh-Ntsefong G, Ngando-Ebongue GF, Koona P, Bell JM, Youmbi E, Ngalle HB, Bilong EG, Madi G, Anaba B. 2012. "Control approaches against vascular wilt disease of Elaeis guineensis Jacq. caused by Fusarium oxysporum f. sp. elaeidis". Journal of Biology and Life Science, 3(1): 160-173.

Ntsomboh-Ntsefong G, Madi G, Nyaka NA, Nsimi MA, Epoh GT, Namuene KS, Fontem LA, Ngando Ebongue GF. 2015a. Vascular wilt disease tolerance status of some oil palm (Elaeis guineensis Jacq.) progenies with local strains of Fusarium oxysporum f. sp. elaeidis in Cameroon. Int. J. Curr. Res. Biosci. Plant Biol., 2: 111-122.

Ntsomboh-Ntsefong G, Epoh-Nguea T, Madi G, Nsimi-Mva A, Ngando Ebongue GF, Kounga Tagne S, Mpondo Mpondo E, Dibong D. 2015b. "Isolation and in vitro characterization of Fusarium oxysporum f. sp. elaeidis, causal agent of oil palm (Elaeis guineensis Jacq.) vascular wilt. Research in Plant Sciences, 3(1): 18-26. DOI:10.12691/plant-3-1-4

Oil world. 2014. Major vegetable oils: world supply and distribution. Oil world.

Oritsejafor JJ. 1986. Weed hosts of Fusarium oxysporum f.sp. elaeidis. Oléagineux, 41: 1-7.

Paul CP. 1995. Fusarium wilt of oil palm. Studies on resistance and pathogenicity. Ph.D. Thesis, University of Bath, Bath.

Renard JL, Gascon JP, Bachy A. 1972. Research on vascular wilt disease of the oil palm. Oléagineux, 27: 581-591.
Smykalová I, Griga M. 2011. Comparison of the effects of Fusarium solani filtrates in vitro and in vivo on the morphological characteristics and peroxidase activity in pea cultivars with different susceptibility. Journal of Plant Pathology, 93: 19-30.

Tailliez B, Ballo KC. 1992. A method of measuring the leaf area of the oil palm. Oléagineux, 47: 537-545.

Tariq RMS, Sahi ST, Ahmad T, Hannan A. 2015. Changes in mineral profile and morphological traits of pea (Pisum sativum L.) as infuenced by Fusarium oxysporum f. sp. Pisi under natural conditions. Journal of Plant Pathology and Microbiology, 5: 244.

Tengoua FF, Bakoumé C. 2008. Pathogenicity of Cameroon strains of Fusarium oxysporum f. sp. elaeidis - the causal agent of oil palm vascular wilt. The Planter, 84: 233-237.

Tucker CC, Chakraborty S. 1997. Quantitative assessment of lesion characteristics and disease severity using digital image processing. Journal of phytopathology, 145: 273-278.

Voui bi BNB, N'guessan KA, Kassik FJM, Tape bi FA, Kamanzi K. 2016. Insectes ravageurs et champignons parasites associés au dépérissement des peuplements de Tectona grandis (teck) régénérés à Téné, zone semi-décidue de Côte d'Ivoire. Int. J. Biol. Chem. Sci., 10(1): $\quad 87-105 . \quad$ DOI : http://ajol.info/index.php/ijbcs

Yergeau E, Sommerville DW, Maheux E, Vujanovic V, Hame C, Whalen JK, StArnaud M. 2006. Relationships between Fusarium population structure, soil nutrient status and disease incidence in field-grown asparagus. FEMS Microbiology Ecology, 58: 394-403. DOI: $\quad 10.1111 /$ j.1574-6941. 2006.00161.x. 